\title{
Distribution characteristics of DNA vaccine encoded with glycoprotein $C$ from Anatid herpesvirus 1 with chitosan and liposome as deliver carrier in ducks
}

Kunfeng Sun 1,2,3, Xin Li 1,2,3, Jinfeng Jiang ${ }^{1}$, Anchun Cheng ${ }^{1,2,3^{*}}$, Mingshu Wang ${ }^{1,2,3^{*}}$, Dekang Zhu ${ }^{2,3}$, Renyong Jia ${ }^{1,2,3}$, Shun Chen ${ }^{1,2,3}$, Yi Zhou $^{3}$, Xiaoyue Chen ${ }^{2,3}$ and Xiaoyu Wang ${ }^{2}$

\begin{abstract}
Background: A eukaryotic expression plasmid encoding glycoprotein C (gC) of Anatid herpesvirus 1 (AnHV-1) (pcDNA3.1-gC) was constructed and validated. The tissue distribution of chitosan/DNA complexes, liposome/DNA complexes and pcDNA3.1-gC alone were evaluated using a quantitative real-time PCR based TaqMan ${ }^{\text {TM }}$ probe following intramuscular administration in ducklings.
\end{abstract}

Results: Compared with pcDNA3.1-gC alone, liposomes universally increased the plasmid DNA copy number at the injection sites, liver, spleen, heart, brain, bursa of Fabricius, and especially in the enteron (esophagus, duodenum, rectum, and cecum). Chitosan also universally increased the plasmid DNA copy number at the injection sites, liver, spleen, heart, brain and esophagus. Compared with lipoplex-gC, higher chitosan-gC plasmid DNA copy numbers were detected at the injection sites, liver, spleen, heart, brain and esophagus. In contrast, compared with lipoplex-gC, lower copy numbers of chitosan-gC plasmid DNA were detected in the duodenum, rectum and cecum.

Conclusions: The results of this study demonstrated that chitosan and liposomes mediated rapid and extensive plasmid distribution in duck tissues, with low levels maintained from $1 \mathrm{~d}$ after DNA vaccination.

Keywords: DNA vaccine, Tissue distribution, Deliver carrier, Chitosan, Liposome, Anatid herpesvirus 1, Glycoprotein C

\section{Background}

Anatid herpesvirus 1 (AnHV-1), belonging to the family Herpesviridae, subfamily Alphaherpesvirinae, genus Mardivirus, is the cause of severe epidemics of duck virus enteritis (DVE), which account for significant economic losses. DVE, also referred to as duck plague, is a highly contagious acute disease of ducks, geese, and swans, which is characterized by hemorrhagic lesions in the blood vessels, gastrointestinal mucosa, and lymphoid tissues [1-3].

As a multifunctional glycoprotein of Alphaherpesvirinae, glycoprotein $\mathrm{C}(\mathrm{gC})$ is involved in viral attachment, stability,

\footnotetext{
* Correspondence: chenganchun@vip.163.com; mshwang@163.com 'Institute of Preventive Veterinary Medicine, Sichuan Agricultural University, Wenjiang, Chengdu City, Sichuan 611130, China

${ }^{2}$ Avian Disease Research Center, College of Veterinary Medicine of Sichuan Agricultural University, 46 Xinkang Road, Ya'an, Sichuan 625014, China Full list of author information is available at the end of the article
}

virulence and other functions [4-15]. Good immune responses and protective efficacy against herpesviruses have been reported in mice and related animals following immunization with DNA vaccines based on the gC gene [16-19]. Our previous study also demonstrated that the AnHV-1 gC protein was highly immunogenic [20].

DNA vaccines, which are a new generation in the vaccine family, are defined by the expression of the exogenous genes in vivo through a delivery system, such as naked plasmid DNA (pDNA) [21]. However, transgene expression occurs only in transduced cells. Therefore, the tissue distribution of genes is an important factor determining the efficacy of in vivo gene transfer.

Generally speaking, the tissue distribution characteristic of an externally administered compound is determined by its interaction with the recipient, and such interaction is regulated by the physicochemical and biological properties 
of the compound and the anatomical and physiological properties of the host. To improve the delivery and cellular uptake of plasmid DNA after in vivo administration, a number of synthetic pDNA delivery vehicles have been developed. These vehicles can currently be divided into cationic polymers and liposomal formulations. Cationic polymers include DNA adsorbed to or entrapped within biodegradable materials such as poly-lactide-co-glycolide or chitosan. Both cationic polymers and liposomal formulations make use of the electrostatic interaction between negatively charged nucleic acids and the positive charges of the synthetic vector [22].

In our research, we developed a novel delivery system, designated pcDNA3.1-gC. A clear understanding of the tissue distribution of pcDNA3.1-gC and its complexes formed with synthetic carrier systems is a prerequisite for a strategy aimed at developing effective in vivo gene transfer methods. Here, we discuss the tissue distribution characteristics of pcDNA3.1-gC, which was systemically administered in the free and complexed forms.

\section{Results}

Construction and identification of pcDNA3.1-gC

As shown in Figure 1a, AnHV-1 gC gene was cloned into the eukaryotic expression vector pcDNA3.1(+), resulting in the DNA vaccine plasmid pcDNA3.1-gC. DNA sequencing showed that pcDNA3.1-gC was correct. The constructed plasmid was subjected to digestion with EcoR I and Xho I. Electrophoretic separation of the digestion products (Figure $1 \mathrm{~b}$ ) showed that the construction of the recombinant plasmid was successful.

\section{Expression of pcDNA3.1-gC in eukaryotic cells}

As shown in Figure 2, intensive fluorescence was found in the cytoplasm of COS-7 cells transfected pcDNA3.1-gC following staining with polyclonal anti-gC hyperimmune serum. In contrast, no fluorescence was detected in COS-7 cells transfected with pcDNA3.1(+).

\section{Biodistribution of pcDNA3.1-gC alone}

The biodistribution of pcDNA3.1-gC in duckling tissues was determined following intramuscular injection. Copy numbers were quantified in different organs at various times after intramuscular injection. As shown in Figure 3, differences in plasmid distribution were observed between organs. One hour post-injection, plasmid DNA was widely distributed among all the analyzed organs. The concentration of plasmid DNA was determined in order of the injection site (liver, kidney, lung, heart, cecum and spleen) at $1 \mathrm{~h}$ post-injection. However, at the highest levels, the concentrations of plasmid DNA in other tissues were 1-2 orders of magnitude lower than at the injection site. Plasmid DNA was detected in all analyzed organs from $1 \mathrm{~h}$ to 10 weeks post-injection. At a

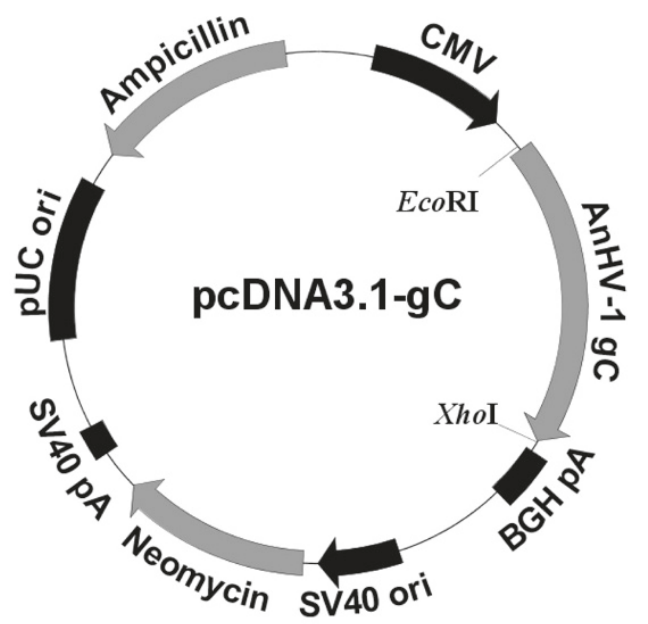

b

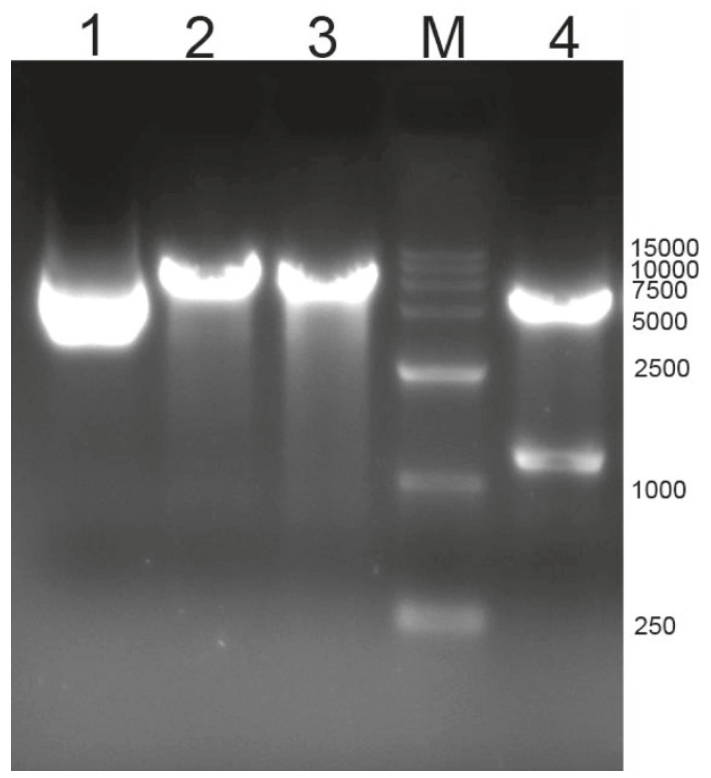

Figure 1 Identification of the recombinant plasmid pcDNA3.1gC a) Schematic representation of pcDNA3.1-gC. The gC gene was inserted into pcDNA3.1 utilizing EcoR I and Xho I sites. b) The digestion products were separated by electrophoresis. Lane 1, pcDNA3.1-gC; Lane 2, single fragment after restriction enzyme digestion with EcoR I; Lane 3, single fragment after restriction enzyme digestion with Xho l; Lane M, DNA marker-DL15000; Lane 4 two fragments after restriction enzyme digestion with Xho I and EcoR I.

the injection site, there was a $3.7 \times 10^{3}$-fold reduction in the plasmid copy numbers at $1 \mathrm{~d}$ compared with $1 \mathrm{~h}$ post-injection. In other organs, there was also a significant decrease at $1 \mathrm{~d}$ compared with $1 \mathrm{~h}$ post-injection. Subsequently, the number of plasmid copies was maintained at a low level. However, higher plasmid copy numbers (approximately 10-fold) were detected at the injection site than in other organs at different times. Minimum copy numbers were found in the 


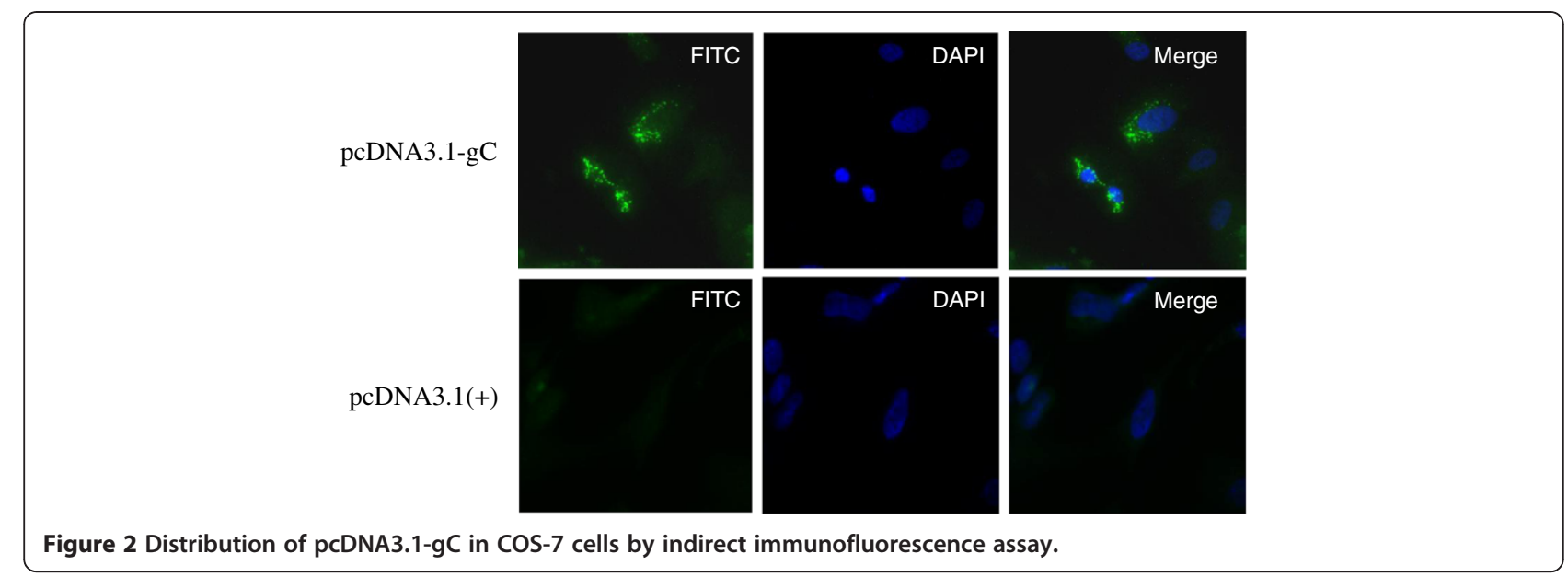

brain, indicating a low capacity of the plasmid to pass the blood-brain barrier.

\section{Biodistribution of lipoplex-gC}

As shown in Figure 4, plasmid DNA was detected in all analyzed organs from $1 \mathrm{~h}$ to 10 weeks post-inoculation. One hour after intramuscular administration, plasmid DNA was distributed widely in all analyzed organs. The highest plasmid DNA concentration was detected at the injection site, cecum, and liver at $1 \mathrm{~h}$. Similar to pcDNA3.1-gC alone, at the highest levels, the concentrations of plasmid DNA in other tissues were still 2-3 orders of magnitude lower than those at the injection site, and the number of plasmid copies was maintained at a low level after $1 \mathrm{~d}$, with minimum copy numbers detected in the brain. However, compared with pcDNA3.1-gC alone, lipids universally increased the quantity of plasmid in different organs, especially in the enteron (esophagus, duodenum, rectum, and cecum).

\section{Biodistribution of chitosan-gC}

As shown in Figure 5, similar to pcDNA3.1-gC alone and lipoplex, chitosan-gC complexes also showed the highest organ distribution at the administration site. One hour after intramuscular administration, plasmid DNA was widely distributed in all analyzed organs. The plasmid copy numbers detected at $1 \mathrm{~d}$ were substantially lower than those detected at $1 \mathrm{~h}$ post-inoculation. In parenchymatous organs, the chitosan/DNA complex group exhibited higher plasmid DNA levels than those detected in the other groups. A notable difference in plasmid DNA levels was detected in the brain, with 39-fold higher levels in the chitosan/DNA group compared with the other groups at $1 \mathrm{~h}$ post-inoculation.

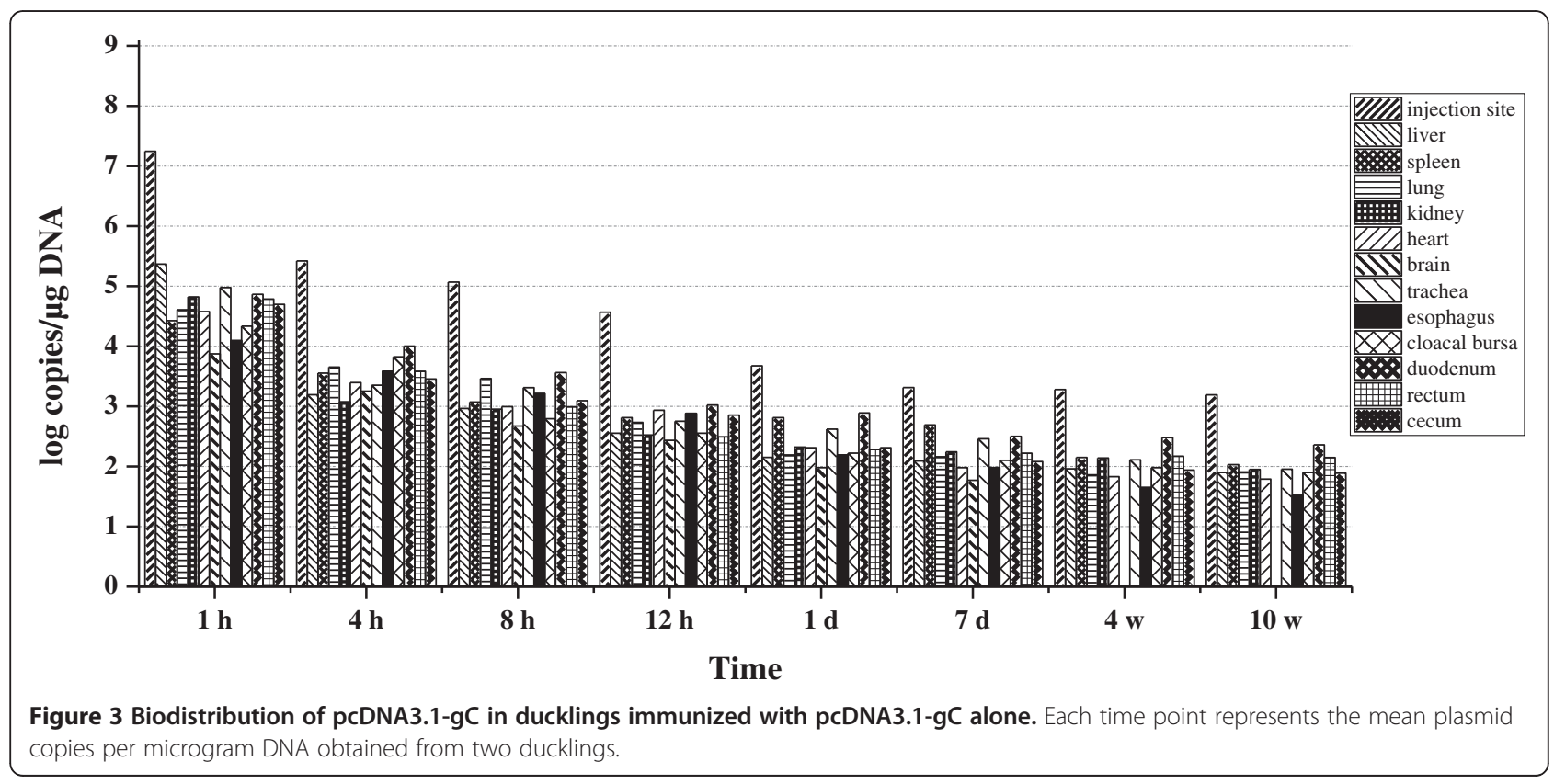




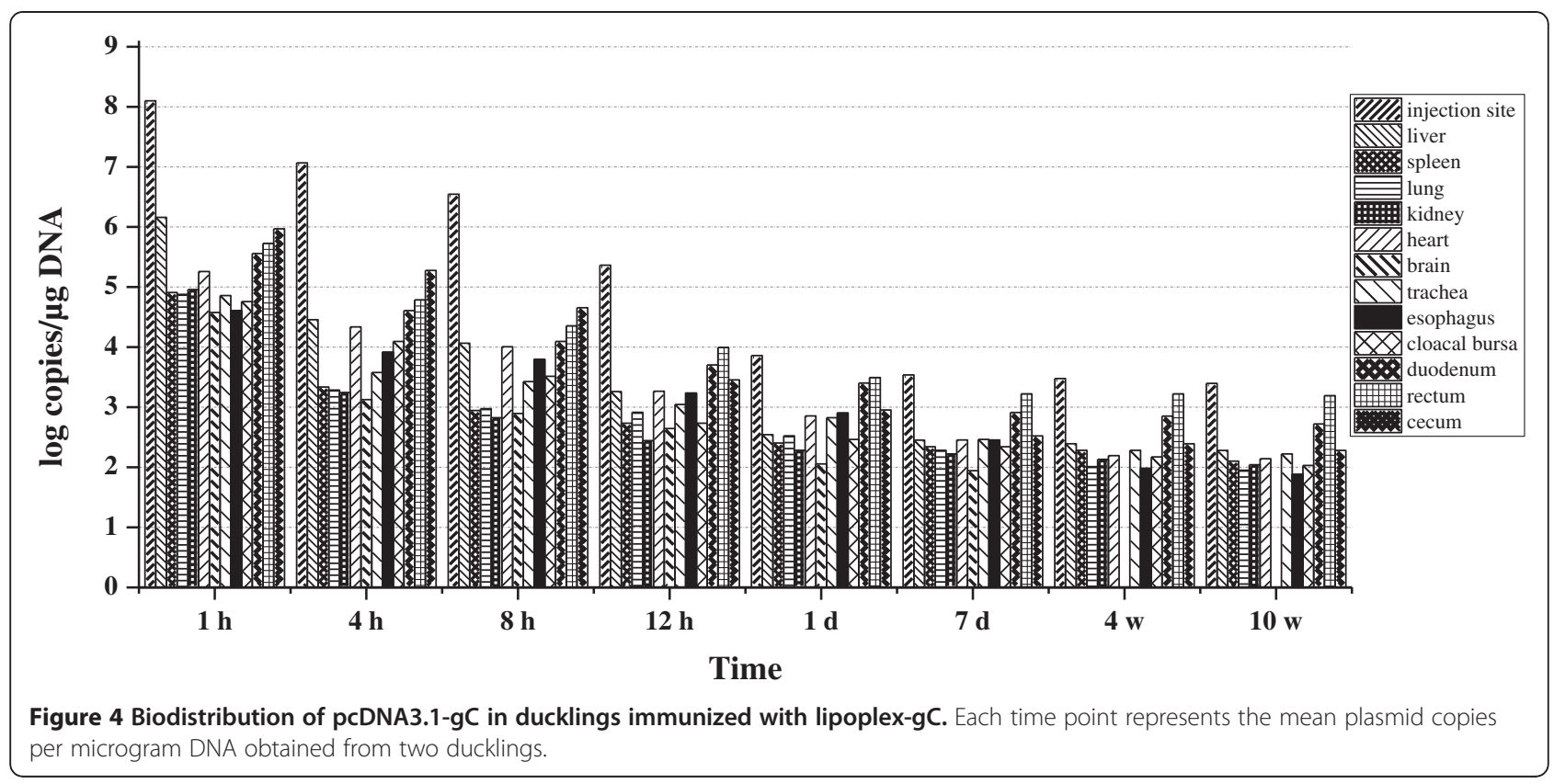

\section{Discussion}

DNA immunization against AnHV-1 has been developed in our laboratory [20]. To increase the efficacy of the AnHV-1 gC DNA vaccine, DNA-lipid complexes and chitosan-DNA nanoparticles were prepared. In the present study, the fates of these complexes and pcDNA3.1-gC alone following intramuscular injection were investigated in ducklings. To our knowledge, this study is the first assessment of the organ distribution and retention time of plasmid DNA administered in lipid complexes or chitosan nanoparticles in ducklings.
More than three decades ago, Wolff showed that the injection of mouse muscle with a DNA plasmid resulted in significant expression of the protein encoded by the plasmid [21]. Progress in the field of DNA vaccination has resulted in the development and the marketing of three veterinary DNA vaccines [23]. The uptake of DNA plasmid by cells upon injection is very inefficient: only a small proportion of the injected material is internalized by cells and results in successful transfection [24]. Therefore, a number of strategies have been used for increasing DNA vaccine potency. Chemical adjuvants for

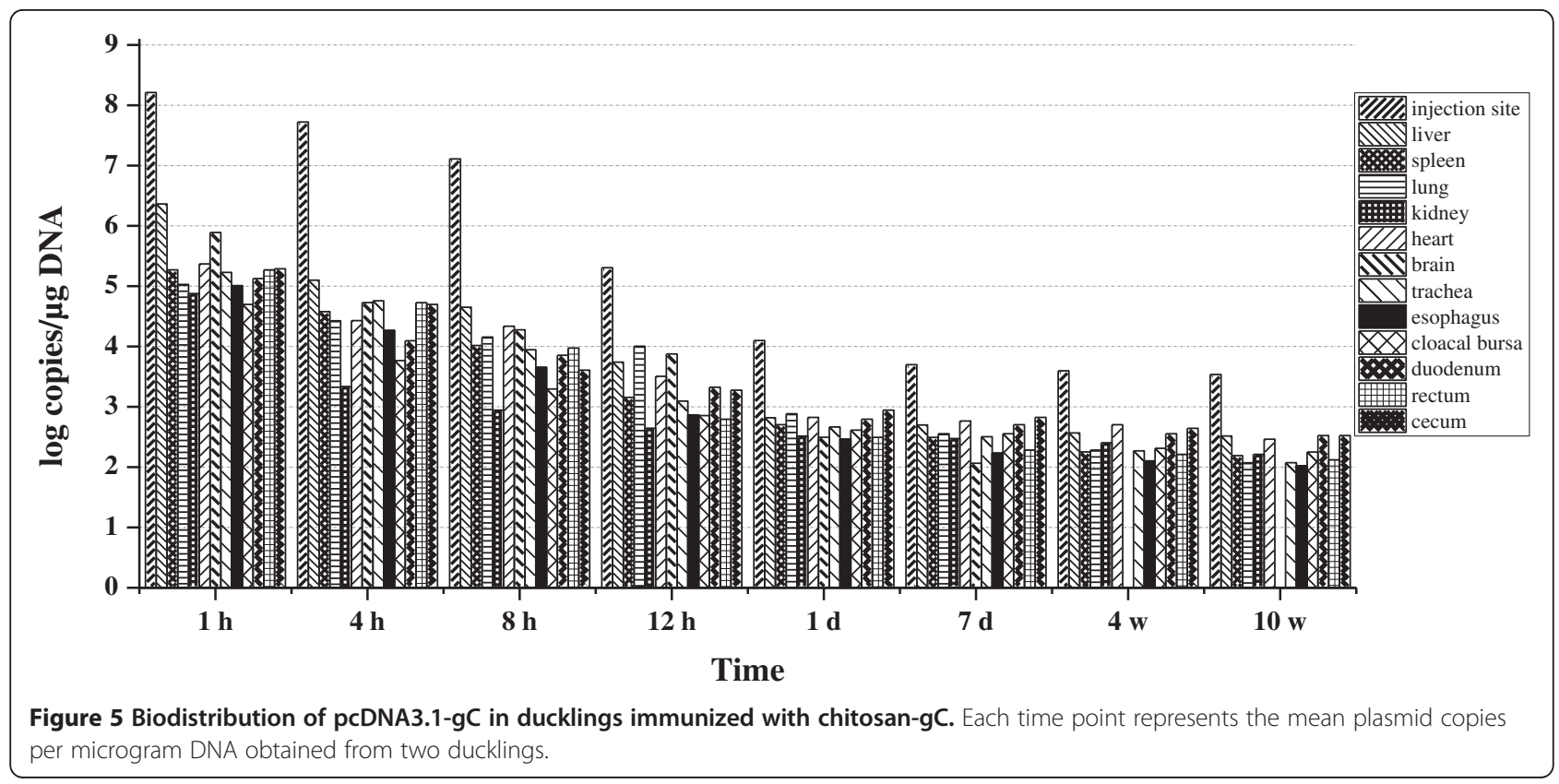


enhancing plasmid DNA expression include liposomes and cationic polymers, both of which have shown promise for enhancing the expression and immunogenicity of plasmid DNA vaccines in animal models [25].

Our results showed that liposomes universally increased the plasmid DNA copy numbers at the injection site, liver, spleen, heart, brain, bursa of Fabricius, and especially in the enteron (esophagus, duodenum, rectum, and cecum), compared with pcDNA3.1-gC alone. Similarly, chitosan also universally increased the plasmid DNA copy numbers at the injection site, liver, spleen, heart, brain and esophagus. These results indicated that liposomes and chitosan enhance the distribution in tissues. In addition, compared with lipoplex-gC, chitosan-gC mediated production of higher numbers of plasmid DNA copies at the injection site, liver, spleen, heart, brain and esophagus. Nevertheless, compared to lipolex-gC, lower copy numbers were detected in duodenum, rectum, and cecum.

In terms of the effects of time after inoculation, the highest concentrations of DNA were detected all the tissues at $1 \mathrm{~h}$ after injection. The number of plasmid copies had decreased by 3-4 orders of magnitude at 1 day after injection. Subsequently, the number of plasmid copies was maintained at a low level and plasmid DNA was still be detected 10 weeks post-injection. Our study is consistent with other studies, which have shown that plasmid remained for several weeks following clearance of the majority of the plasmid within the first $24 \mathrm{~h}$ postinoculation [26-28]. Additionally, results based on indirect immunohistochemical staining (IHC) have shown that the $\mathrm{gC}$ proteins are still found in the liver, bursa of Fabricius, duodenum, caecum and rectum in the intramuscular injection group at 10 weeks post-inoculation [29].

Transfection of cells by chitosan nanoparticles and lipoplexes occurs in three phases: (1) cellular uptake by formation of endosomes into the target cells; (2) release from the endosome; (3) entry of plasmid DNA into the cell nucleus [30,31]. Liposomes can protect the nucleic acid from extracellular degradation, ensuring appropriate tissue targeting, and facilitating the delivery of functional DNA into the cell $[32,33]$. As a cationic polymers, chitosan (CS) is an effective, naturally-occurring material used for synthesizing nanoparticles with advantageous properties such as low toxicity, low immunogenicity and excellent biocompatibility [34,35]. Accordingly, following inoculation with chitosan/DNA or liposome/DNA complexes, plasmid DNA diffuses from the injection site and/or degrades more slowly because of a liposomes or chitosan depot effect. The liposome/DNA or chitosan/ DNA depot is thought to provide some protection against nucleases, thus extending the half-life of the plasmid DNA at the injection site [30]. It has been shown that formulation of DNA vaccines into liposomes enhances cellular and humoral immunity [34,35]. Our previous study also showed that chitosan significantly improved $\mathrm{CD}_{4}^{+}$and $\mathrm{CD} 8^{+} \mathrm{T}$ cell responses to at least 6 weeks post-injection in Balb/c mice [36]. The immune responses to these formulations and protection against Anatid herpesvirus 1 challenge in ducks are currently being analyzed.

Fluorescence-based quantitative real-time PCR (qPCR) is commonly regarded as a straightforward, mature and ubiquitous means of molecular biology [37]. Probe-based qPCR technology is recommended as the reference technique for monitoring gene transfer biodistribution [38]. Therefore, in our previous study, we established a qPCR protocol based on the use of a TaqMan ${ }^{\mathrm{TM}}$ probe [39]. In contrast to previous studies, equivalent amounts of DNA $(100 \mu \mathrm{g})$ were injected in the form of pcDNA3.1-gC, DNA-lipid complexes and chitosan-DNA nanoparticles and $200 \mathrm{ng}$ of gDNA were used in each PCR reaction by preparation of the appropriate dilution ratios. Because we observed that there existed the inhibition due to the gDNA matrix, which affected quantification using qPCR (data not shown). This was consistent with other studies [40]. In the present study, $100 \mu \mathrm{g}$ of plasmid was injected for each group. The same amount of each tissue was collected.

In summary, we successfully used chitosan and lipid formulations for DNA vaccination in ducklings. Compared with pcDNA3.1-gC alone, chitosan/DNA and DNA/lipid complexes improved the efficiency of plasmid distribution. The complexes were rapidly absorbed, and extensive and relatively long-term distribution at low concentrations was observed following DNA vaccination in ducklings.

\section{Conclusions}

In this study, we succeeded in constructing a eukaryotic expression plasmid encoding the AnHV-1 gC gene. Endonuclease digestion and indirect immunofluorescence confirmed the identity of the construct and quantitative real-time PCR analysis demonstrated rapid and extensive distribution of the plasmid, which was subsequently maintained at a low level after one day. Thus, chitosan and lipid mediate efficient plasmid distribution and facilitate long-term maintenance of the plasmid.

\section{Methods}

\section{Plasmid preparation}

As shown in Figure 1a, pcDNA3.1-gC, which encoded the AnHV-1glycoprotein $\mathrm{C}$, was generated by cloning gC gene into the EcoR I and Xho I sites of pcDNA3.1(+) (Invitrogen, USA) vector according to the manufacturer's protocol. The purified $\mathrm{gC}$ gene was obtained from pMD18-gC [41] by restriction enzyme digestion (EcoR I and Xho I) (Takara, Japan). The pcDNA3.1-gC plasmid was transformed into $E$. coli JM109. By means of a fedbatch process for high cell density cultivation, E. coli 
harboring pcDNA3.1-gC was produced using a Biostat ${ }^{\circledR}$ Cplus fermenter (Sartorius, Germany). The fermentation broth was centrifuged at $5000 \times g$ for $10 \mathrm{~min}$ in an Avanti J-26XP Centrifuge (Beckman Coulter, USA). Preparation and purification of plasmid DNA were based on alkaline lysis with SDS (maxipreparation) and precipitation with polyethylene glycol as described by Sambrook [42]. The purity of plasmid DNA was assessed by agarose gel electrophoresis and using the $260 \mathrm{~nm}$ and $280 \mathrm{~nm}$ absorbance ratio $\left(\mathrm{A}_{260 / 280}\right)$. The purified DNA was stored at $-20^{\circ} \mathrm{C}$.

\section{Transient expression and indirect immunofluorescence (IIF) assay}

The pcDNA3.1-gC was first transfected into COS-7 cells using Lipofectamine 2000 (Invitrogen, USA) according to the manufacturer's instructions. Briefly, plasmid DNA $(4 \mu \mathrm{g})$ was diluted with $250 \mu \mathrm{L}$ serum-free DMEM media. Lipofectamine $(10 \mu \mathrm{L})$ was diluted with the same media. The diluted plasmid DNA and Lipofectamine solutions were then mixed. The DNA-Lipofectamine solutions were added to six-well culture plates containing coverslips. After incubation at $37^{\circ} \mathrm{C}$ for $48 \mathrm{~h}$, cells were fixed with $4 \%$ paraformaldehyde. After blocking for $1 \mathrm{~h}$ in phosphatebuffered saline (PBS) containing $10 \% \mathrm{BSA}$ at $37^{\circ} \mathrm{C}$, the coverslip was incubated with the anti-gC IgG antibodies $(1: 100)$ at $4^{\circ} \mathrm{C}$ overnight, and then treated with FITC-conjugated goat anti-rabbit IgG (Sino-American Biotechnology Co., China) (1:100) for $45 \mathrm{~min}$ at $37^{\circ} \mathrm{C}$. The stained cells were examined with the Nikon $80 \mathrm{i}$ fluorescence microscope (Tokyo, Japan).

Preparation of DNA-lipid complexes (designated lipoplex-gC) DNA-lipid complexes were prepared as described by Rosada [43] and Torchilin [44]. The required amounts of all lipid stock solutions in chloroform (PC/CH/ODA 5:4:1 molar) were mixed and dried to a thin film using a rotary evaporator in vacuum for $1 \mathrm{~h}$. The films were hydrated in sterile water above its phase transition temperature. The hydrated lipid solution was then sonicated and passed sequentially through two polycarbonate membranes $(0.45 \mu \mathrm{m}$ nominal diameter and $0.22 \mu \mathrm{m}$ nominal diameter; 15 times per membrane). DNA (pcDNA3.1-gC) was mixed with the extruded liposomes at a lipid/DNA mass ratio of $1 / 50$, frozen, and vacuum freeze-dried overnight. Controlled rehydration of the dry powders with PBS resulted in the formation of liposomes encapsulating the DNA.

\section{Preparation of chitosan-DNA nanoparticles (designated chitosan-gC polyplexes)}

Chitosan (MW $55 \mathrm{kDa}$, deacetylation degree 90\%, medical grade) was kindly provided by Golden-Shell Biochemical Co., Ltd (China). It was purified by reprecipitation from the filtered $1 \%$ acetic acid solution with ammonium hydroxide. The precipitate was washed with water and dried under vacuum. The purified chitosan was dissolved in $1 \%$ acetic acid with gentle heating and the $\mathrm{pH}$ of the solution was adjusted to 5.5-5.7 with sodium hydroxide. The solution was diluted to $0.03 \%$ chitosan $(\mathrm{w} / \mathrm{v})$ and $5 \mathrm{mM}$ acetate. The $\mathrm{pH}$ of the chitosan stock solution was readjusted to $\mathrm{pH} 5.5$ and sterile filtered through a $0.22 \mu \mathrm{m}$ filter. The solution was stored at $4^{\circ} \mathrm{C}$. A chitosan solution (0.03\% in $5 \mathrm{mmol} / \mathrm{L}$ sodium acetate buffer, $\mathrm{pH} 5.5)$ and a DNA solution $(100 \mu \mathrm{g} / \mathrm{mL}$ in $10 \mathrm{mmol} / \mathrm{L}$ sodium sulfate solution) were preheated to $55^{\circ} \mathrm{C}$ separately. An equal volume of both solutions were quickly mixed together and vortexed for 15-30 s (amino group to phosphate group ratio (N/P ratio) of 3:1). The final volume of the mixture in each preparation was limited to a maximum of $500 \mu \mathrm{L}$ in order to yield uniform nanoparticles. The homogeneity of chitosan-gC polyplex nanoparticles was analyzed by transmission electron microscopy (Hitachi H-600, Tokyo, Japan) as described by Jiang [45].

\section{Animal vaccination and sample collection}

This study was conducted with 80 AnHV-1-free Peking ducks (28 days old) from an AnHV-1-free farm. The AnHV-1 status was confirmed by qualitative PCR as described by Song [46]. The ducks were fed with commercial duck pellets. Water troughs that were deep enough for the ducks to float and splash were placed in each room. Each room also had a partially enclosed dry retreat with wood shavings for the ducks to sit on. The ducklings were randomly divided into four equal groups in this study. Using $5 \mathrm{~mL}$ syringes, ducks in groups 1-3 were inoculated by the intramuscular route with pcDNA3.1-gC alone, lipoplex-gC, and chitosan-gC polyplex each containing equivalent amounts of plasmid DNA $(100 \mu \mathrm{g})$. Ducks in group 4 were inoculated with pcDNA3.1(+) as a control. At each of eight sampling times, two vaccinated ducks per group were chosen randomly for sampling. The liver, spleen, kidney, lung, trachea, esophagus, heart, brain, duodenum, rectum, cecum, injection site and bursa of Fabricius were collected at $1 \mathrm{~h}, 4 \mathrm{~h}, 8 \mathrm{~h}, 12 \mathrm{~h}, 1 \mathrm{~d}, 7 \mathrm{~d}, 4$ weeks and 10 weeks postinoculation. Each solid tissue sample was transferred to a labeled bag, snap-frozen in liquid nitrogen, and stored at $-80^{\circ} \mathrm{C}$. All animal work was conducted with the approval of the Sichuan Agricultural University Animal Ethics Committee.

\section{DNA extraction from tissues}

Total DNA was isolated from each of the harvested tissues by phenol-chloroform extraction [47]. Tissue (50 mg) was minced and suspended in $500 \mu \mathrm{L}$ proteinase digestion buffer $(10 \mathrm{mmol} / \mathrm{L}$ Tris- $\mathrm{HCl}, 0.1 \mathrm{~mol} / \mathrm{L}$ EDTA, $0.5 \%$ SDS, $20 \mu \mathrm{g} / \mathrm{mL}$ RNase $\mathrm{A}, \quad \mathrm{pH} \quad 8.0)$ and 
homogenized using a tissue homogenizer (IKA, Germany). After incubation at $37^{\circ} \mathrm{C}$ for $1 \mathrm{~h}$, homogenized tissue was digested with proteinase $\mathrm{K}(100 \mu \mathrm{g} / \mathrm{mL})$ overnight at $55^{\circ} \mathrm{C}$, extracted three times with equal volumes of buffered phenol and chloroform and precipitated with 2.5 volumes of ethanol. DNA was pelleted by centrifugation at $13,000 \times g$ for $10 \mathrm{~min}$, rinsed in $70 \%$ ethanol and air dried under an isolation hood before being resuspending in $50 \mu \mathrm{L}$ TE buffer ( $\mathrm{pH}$ 8.0). DNA concentrations were determined by UV absorption at $260 \mathrm{~nm}$. The $A_{260 / 280}$ absorbance ratio for each sample was confirmed to be $\geq 1.8$. Each sample was analyzed by electrophoresis in a $0.8 \%$ agarose gel to ensure that the DNA migrated predominantly as a high molecular weight band and exhibited no detectable RNA contamination. The tissue DNA was stored at $-20^{\circ} \mathrm{C}$ for further analysis.

\section{Quantitative real-time PCR assays}

The levels of $\mathrm{gC}$ in negative and positive control DNA (from non-injected or pcDNA3.1-gC), and test sample DNA were quantified by a qPCR assay as described previously [39]. The primers used for PCR amplification were forward primer (FP), 5'-GAAGGACGGAATGGTGG AAG- ${ }^{\prime}$, and reverse primer (RP), $5^{\prime}$-AGCGGGTAACGAG ATCTAATATTGA-3', which amplify a 78 bp fragment of the AnHV-1 gC gene (GenBank; Accession No.: EU076811). A 23-bp TaqMan probe (FAM-CCAATGCATCGATCATC CCGGAA-TAMRA) complementary to an internal region between the two primers was selected and synthesized with a FAM (6-carboxyfluorescein) reporter molecule at the 5 'end and a TAMRA (tetra-methylcarboxyrhodamine) quencher molecule at the $3^{\prime} \mathrm{end}$. The qPCR reactions were carried out using a Premix Ex Taq ${ }^{\mathrm{TM}}$ kit (Takara, Japan) with an iCycler $\mathrm{iQ}^{\mathrm{TM}}$ Multicolor Real-Time PCR Detection System (Bio-Rad, USA). All qPCR assays were performed using the same format. The amplification was performed in a $20 \mu \mathrm{L}$ reaction mixture containing $2.0 \mu \mathrm{L}$ DNA solution (200 ng of tissue DNA was used by preparing different dilution ratios), $10 \mu \mathrm{L} 2 \times$ Premix Ex Taq ${ }^{\mathrm{TM}}, 0.5 \mu \mathrm{mol} / \mathrm{L}$ each primer and $0.25 \mu \mathrm{mol} / \mathrm{L}$ fluorogenic probe. The two-step PCR cycling conditions were as follows: initial denaturation and hot-start Taq DNA polymerase activation at $95^{\circ} \mathrm{C}$ for $5 \mathrm{~min}, 45$ cycles of denaturation at $94^{\circ} \mathrm{C}$ for $5 \mathrm{~s}$, primer annealing and extension at $53^{\circ} \mathrm{C}$ for $30 \mathrm{~s}$ with fluorescence acquisition during each annealing and extension stage. The tests were carried out by using the $0.2 \mathrm{~mL}$ PCR tubes (Axygen, USA). The reaction, data acquisition, and analysis were performed using iCycler $\mathrm{iQ}^{\mathrm{TM}}$ Optical detection system software (Version 3.1). A plasmid DNA sample was diluted to contain $1 \times 10^{1}-1 \times 10^{8}$ copies per test tube and used as a standard series.
Competing interests

The authors declare that they have no competing interests.

\section{Authors' contributions}

$\mathrm{KFS}, \mathrm{XL}$, JFJ carried out most of the experiments. KFS, XL wrote the manuscript. ACC and MSW critically revised the manuscript and designed the experiments. DKZ, RYJ, SC, YZ, XYC and XYW helped to perform the experiments and wrote the manuscript. All authors read and approved the final manuscript.

\section{Acknowledgments}

This work was supported by grants from the Major State Basic Research Development Program of China (973 Program) (2011CB111606), the National Natural Science Foundation of China (31072157), the Innovative Research

Team Program in Education Department of Sichuan Province(12TD005), the Science and Technology Support Programs of Sichuan Province, China (2010HH0013, 2011ZO0034, and 2011JO0040) and China Agricultural Research System (CARS-43-8).

\section{Author details}

${ }^{1}$ Institute of Preventive Veterinary Medicine, Sichuan Agricultural University, Wenjiang, Chengdu City, Sichuan 611130, China. ${ }^{2}$ Avian Disease Research Center, College of Veterinary Medicine of Sichuan Agricultural University, 46 Xinkang Road, Ya'an, Sichuan 625014, China. ${ }^{3}$ Key Laboratory of Animal Disease and Human Health of Sichuan Province, Sichuan Agricultural University, Wenjiang, Chengdu City, Sichuan 611130, China.

Received: 17 March 2012 Accepted: 7 March 2013

Published: 16 March 2013

\section{References}

1. Sandhu TS, Metwally SA: Duck Virus Enteritis (Duck Plague). In Diseases of Poultry. 12th edition. Edited by Saif YM, Fadly AM, Glisson JR, McDougald LR, Nolan LK, Swayne DE. Ames: Blackwell Publishing; 2008:384-393.

2. Davison A, McGeoch D: New species Anatid herpesvirus 1 in genus Mardivirus, subfamily Alphaherpesvirinae, family Herpesviridae, ICTV Official Taxonomy: Updates since the 8th Report; Feb 23. 2012. http://talk.ictvonline.org/files/ ictv_official_taxonomy_updates_since_the_8th_report/m/vertebrate-official/ 4174.aspx.

3. ICTV Master Species List 2012 v1. http://talk.ictvonline.org/files/ictv_documents/ $\mathrm{m} / \mathrm{msl} / 4440$.aspx.

4. Mettenleiter TC, Schreurs C, Zuckermann F, Ben-Porat T, Kaplan AS: Role of glycoprotein glll of pseudorabies virus in virulence. J Virol 1988, 62:2712-2717.

5. Friedman HM, Cohen GH, Eisenberg RJ, Seidel CA, Cines DB: Glycoprotein C of herpes simplex virus 1 acts as a receptor for the C $3 \mathrm{~b}$ complement component on infected cells. Nature 1984, 309:633-635.

6. Awasthi S, Lubinski JM, Friedman HM: Immunization with HSV-1 glycoprotein $C$ prevents immune evasion from complement and enhances the efficacy of an HSV-1 glycoprotein D subunit vaccine. Vaccine 2009, 27:6845-6853.

7. Livingston JR, Sutherland MR, Friedman HM, Pryzdial ELG: Herpes simplex virus type 1-encoded glycoprotein $C$ contributes to direct coagulation factor X-virus binding. Biochem J 2006, 393:529-535.

8. Hook LM, Lubinski JM, Jiang M, Pangburn MK, Friedman HM: Herpes simplex virus type 1 and 2 glycoprotein $C$ prevents complementmediated neutralization induced by natural immunoglobulin $\mathrm{M}$ antibody. J Virol 2006, 80:4038-4046.

9. Hook LM, Huang J, Jiang M, Hodinka R, Friedman HM: Blocking antibody access to neutralizing domains on glycoproteins involved in entry as a novel mechanism of immune evasion by herpes simplex virus type 1 glycoproteins C and E. J Virol 2008, 82:6935-6941.

10. Jarosinski KW, Osterrieder N: Further analysis of Marek's disease virus horizontal transmission confirms that UL44 $(\mathrm{gC})$ and UL13 protein kinase activity are essential, while US2 is nonessential. J Virol 2010, 84:7911-7916.

11. Azab W, Tsujimura K, Maeda K, Kobayashi K, Mohamed YM, Kato K, Matsumura T, Akashi H: Glycoprotein C of equine herpesvirus 4 plays a role in viral binding to cell surface heparan sulfate. Virus Research 2010, 151:1-9.

12. Schreurs C, Mettenleiter TC, Zuckermann F, Sugg N, Ben-Porat T: Glycoprotein glll of pseudorabies virus is multifunctional. J Virol 1988, 62:2251-2257. 
13. Herold BC, WuDunn D, Soltys N, Spear PG: Glycoprotein C of herpes simplex virus type 1 plays a principal role in the adsorption of virus to cells and in infectivity. J Virol 1991, 65:1090-1098.

14. Ben-Porat T, DeMarchi JM, Lomniczi B, Kaplan AS: Role of glycoproteins of pseudorabies virus in eliciting neutralizing antibodies. Virology 1986, 154:325-334.

15. Adamiak B, Trybala E, Mardberg K, Johansson M, Liljeqvist J-A, Olofsson S, Grabowska A, Bienkowska-Szewczyk K, Szewczyk B, Bergstrom T: Human antibodies to herpes simplex virus type 1 glycoprotein $C$ are neutralizing and target the heparan sulfate-binding domain. Virology 2010, 400:197-206.

16. Gupta PK, Saini M, Gupta LK, Rao VDP, Bandyopadhyay SK, Butchaiah G, Garg GK, Garg SK: Induction of immune responses in cattle with a DNA vaccine encoding glycoprotein $\mathrm{C}$ of bovine herpesvirus-1. Vet Microbiol 2001, 78:293-305.

17. Xiao S, Chen H, Fang L, Liu C, Zhang H, Jiang Y, Hong W: Comparison of immune responses and protective efficacy of suicidal DNA vaccine and conventional DNA vaccine encoding glycoprotein C of pseudorabies virus in mice. Vaccine 2004, 22:345-351.

18. Fischer L, Barzu S, Andreoni C, Buisson N, Brun A, Audonnet JC: DNA vaccination of neonate piglets in the face of maternal immunity induces humoral memory and protection against a virulent pseudorabies virus challenge. Vaccine 2003, 21:1732-1741.

19. Gerdts V, Jöns A, Makoschey B, Visser N, Mettenleiter TC: Protection of pigs against Aujeszky's disease by DNA vaccination. J Gen Virol 1997, 78:2139-2146.

20. Lian B, Cheng A, Wang M, Zhu D, Luo Q, Jia R, Liu F, Han X, Chen X: Induction of immune responses in ducks with a DNA vaccine encoding duck plague virus glycoprotein C. Virol J 2011, 8:214.

21. Wolff JA, Malone RW, Williams P, Chong W, Acsadi G, Jani A, Felgner PL: Direct gene transfer into mouse muscle in vivo. Science 1990, 247:1465-1468.

22. Jechlinger W: Optimization and delivery of plasmid DNA for vaccination. Expert Rev Vaccines 2006, 5:803-825.

23. Faurez F, Dory D, Le Moigne V, Gravier R, Jestin A: Biosafety of DNA vaccines: New generation of DNA vectors and current knowledge on the fate of plasmids after injection. Vaccine 2010, 28:3888-3895.

24. Ulmer JB, Wahren B, Liu MA: Gene-based vaccines: recent technical and clinical advances. Trends Mol Med 2006, 12:216-222.

25. Greenland JR, Letvin NL: Chemical adjuvants for plasmid DNA vaccines. Vaccine 2007, 25:3731-3741.

26. Zheng F, Sun X, Liu H, Wu X, Zhong N, Wang B, Zhou G: Distribution and expression in vitro and in vivo of DNA vaccine against lymphocystis disease virus in Japanese flounder (Paralichthys olivaceus). Chin J Oceanol Limnol 2010, 28:67-74.

27. Rajeshkumar S, Venkatesan C, Sarathi M, Sarathbabu V, Thomas J, Basha KA, Hameed ASS: Oral delivery of DNA construct using chitosan nanoparticles to protect the shrimp from white spot syndrome virus (WSSV). Fish Shellfish Immunol 2009, 26:429-437.

28. Gravier R, Dory D, Laurentie M, Bougeard S, Cariolet R, Jestin A: In vivo tissue distribution and kinetics of a pseudorabies virus plasmid DNA vaccine after intramuscular injection in swine. Vaccine 2007, 25:6930-6938.

29. Shen F, Jing J, Cheng A, Wang M, Lu L, Jia R, Zhu D, Chen X, Sun T: Antigenic expression and distribution of chitosan/pcDNA-DPV-gC gene in the vaccinated ducklings. Scientia Agricultura Sinica 2011, 44:3909-3917.

30. Zhao K, Shi X, Zhao Y, Wei H, Sun Q, Huang T, Zhang X, Wang Y: Preparation and immunological effectiveness of a swine influenza DNA vaccine encapsulated in chitosan nanoparticles. Vaccine 2011, 29:8549-8556.

31. Khalil IA, Kogure K, Akita H, Harashima H: Uptake pathways and subsequent intracellular trafficking in nonviral gene delivery. Pharmacol Rev 2006, 58:32-45.

32. Felgner PL, Gadek TR, Holm M, Roman R, Chan HW, Wenz M, Northrop JP, Ringold GM, Danielsen M: Lipofection: a highly efficient, lipid-mediated DNA-transfection procedure. Proc Natl Acad Sci USA 1987, 84:7413-7417.

33. Felnerova D, Viret J-F, Glück R, Moser C: Liposomes and virosomes as delivery systems for antigens, nucleic acids and drugs. Curr Opin Biotechnol 2004, 15:518-529.

34. Schwendener RA, Ludewig B, Cerny A, Engler O: Liposome-based vaccines. Methods Mol Biol 2010, 605:163-175.

35. Wang J, Hu J-h, Li F-q, Liu G-z, Zhu Q-g, Liu J-y, Ma H-j, Peng C, Si F-g: Strong cellular and humoral immune responses induced by transcutaneous immunization with $\mathrm{HBsAg}$ DNA-cationic deformable liposome complex. Exp Dermatol 2007, 16:724-729.
36. Jiang J, Cheng A, Wang M, Lu L, Zhu D, Jia R, Chen X: The immunoreaction in Balb/c mice immunized with duck enteritis virus $\mathrm{gC}$ genetic vaccine with chitosan as deliver carrier. Scientia Agricultura Sinica 2011, 44:3454-3462.

37. Bustin SA, Beaulieu J-F, Huggett J, Jaggi R, Kibenge FSB, Olsvik PA, Penning LC, Toegel S: MIQE précis: Practical implementation of minimum standard guidelines for fluorescence-based quantitative real-time PCR experiments. BMC Mol Biol 2010, 11:74.

38. Gonin P, Gaillard C: Gene transfer vector biodistribution: pivotal safety studies in clinical gene therapy development. Gene Ther 2004, 11(Suppl 1):S98-S108.

39. Zou Q, Sun K, Cheng A, Wang M, Xu C, Zhu D, Jia R, Luo Q, Zhou Y, Chen Z, Chen $X$ : Detection of anatid herpesvirus $1 \mathrm{gC}$ gene by TaqMan fluorescent quantitative real-time PCR with specific primers and probe. Virol J 2010, 7:37.

40. Fu J, Li D, Xia S, Song H, Dong Z, Chen F, Sun X, Tang Z: Absolute quantification of plasmid DNA by real-time PCR with genomic DNA as external standard and its application to a biodistribution study of an HIV DNA vaccine. Anal Sci 2009, 25:675-680.

41. Xu C, Li X, Xin H, Lian B, Cheng A, Wang M, Zhu D, Jia R, Luo Q, Chen X: Cloning and molecular characterization of $\mathrm{gC}$ gene of duck plague virus. Chinese Veterinary Science 2008, 38:1038-1044.

42. Sambrook J, Russell DW: Molecular Cloning: A Laboratory Manual. 3rd edition. Cold Spring Harbor, New York: Cold Spring Harbor Laboratory Press; 2001.

43. Rosada RS, de la Torre LG, Frantz FG, Trombone AP, Zárate-Bladés CR, Fonseca DM, Souza PR, Brandão IT, Masson AP, Soares ÉG, et al: Protection against tuberculosis by a single intranasal administration of DNA-hsp65 vaccine complexed with cationic liposomes. BMC Immunol 2008, 9:38.

44. Torchilin V, Weissig V: Liposomes: A Practical Approach. 2ed edition. Oxford: Oxford University Press; 2003.

45. Jiang J: Studies on the immunogenesis in BALB/C mice immunized with $g C$ genetic vaccine of duck enteritis virus. Veterinary Medicine: Master thesis. Sichuan agriculture university; 2010

46. Song Y, Cheng A, Wang M, Liu F, Liao Y, Yuan G, Han X, Xu C, Chen X: Development and application of PCR to detect duck plague virus. Chinese Journal of Veterinary Medicine 2005, 41:17-20.

47. Barry ME, Pinto-González D, Orson FM, McKenzie GJ, Petry GR, Barry MA: Role of endogenous endonucleases and tissue site in transfection and CpG-mediated immune activation after naked DNA injection. Hum Gene Ther 1999, 10:2461-2480.

\section{doi:10.1186/1743-422X-10-89}

Cite this article as: Sun et al:: Distribution characteristics of DNA vaccine encoded with glycoprotein C from Anatid herpesvirus 1 with chitosan and liposome as deliver carrier in ducks. Virology Journal 2013 10:89.

\section{Submit your next manuscript to BioMed Central and take full advantage of:}

- Convenient online submission

- Thorough peer review

- No space constraints or color figure charges

- Immediate publication on acceptance

- Inclusion in PubMed, CAS, Scopus and Google Scholar

- Research which is freely available for redistribution 